\title{
How safe is organic farming by subsistence farmers from developing countries in the face of persistent organic pollutants in the environment? \\ Olowoyo $\mathrm{JO}^{1,2}$ and Mugivhisa $\mathrm{LL}^{1}$
}

\section{Department of Biology, Sefako Makgatho Health Sciences University, Pretoria, P.O.Box 139, Medunsa, 0204.}

\section{Toxicology Centre, University of Saskathchewan, Saskatoon, Canada.}

\section{ABSTRACT}

Organic farming products are fast gaining acceptance from consumers all over the world due to the perceived belief that they are safe for human consumption. In recent years, there has been an increase in the levels of persistent organic and inorganic pollutants in the environment. These pollutants may be found in materials such as sewage sludge, treated wastewater, farmyard manure (human and animal feaces and urine) that are used for organic farming. The present review examined through literature the presence of these emerging pollutants in crops that are cultivated from farming activities practicing organic farming. The review highlighted and documented various pollutants that may be found in crops due to non-compliance with legislation establishing organic farming. The need to develop a robust method for identifying safe products from organic farming was highlighted. The impact of non-compliance and lack of proper education on the peasant farmers practicing backyard farming was also enumerated.

Keywords: Organic farming, Persistent Organic Pollutants, Crops, Peasant farmers, Education.

\section{INTRODUCTION}

Organic farming is fast gaining prominence all over the world due to the perceived believe that products derived from it are safe for human consumption (Mugivhisa and Olowoyo, 2015). Organic farming is also believed to be a safe method of producing food for the nation without having any serious negative influence on the environment since plant, animal and other types of biodegradable 
waste are used in the process (Seufert et al. 2017). As at present, organic products remains the most recognized safest and easily interpreted food label in most registered stores by consumers (Rigby and Cáceres, 2001).

The main objectives of organic farming are to enhance farmers' livelihoods, increase agricultural production within the less privileged group and also reduce the negative impact of inorganic fertilizers on the environment (Scialabba and Hattam, 2002). Altenbuchner et al. (2017) further mentioned that the goal of organic farming also includes women empowerment with the aim of gaining access to education thereby assisting them to make informed decision that may affect their health and overall wellbeing. Through the introduction of organic farming, it is also possible for women to apply their indigenous knowledge and embrace their role as 'keeper of seeds' which in turn encourages biodiversity (Farnworth \& Hutchings, 2009).

\section{What is organic farming?}

The definition and guidelines as to what organic farming really stands for varies from region to region and from countries to countries. The European Union Act EC 834/2007c that came into existence in 2009, defined organic farming "as a way of producing agricultural goods that restrict the use of off-farm inputs in favour of other farming practices (cultural, biological and mechanical) which should be established on any farm after the period of conversion". The Regulation considers environmental protection, preservation of natural resources (including biodiversity), application of high animal welfare standards and production method based on natural substances and processes. The EU Act principle includes the production of food of high quality with the restriction of the use of external inputs and the strict limitation of the use of chemically synthesised inputs to exceptional cases.

In Africa, according to International Federation of Organic Agriculture Movements (2008), most certified organic product in Africa is mainly towards the export markets. Most of the African 
countries rely mainly on foreign standards and as such most of the certified organic product have been carried out following the EU regulation for organic products. However, some countries and regions do have existing policy that are developed from EU Act on organic farming.

From East Africa, the policy on organic farming or production (EAS 456: 2007) stated "the operator (farmer in this case) shall avoid using chemical products that may endanger human health or the environment. Where there are products that are considered to be less harmful, they shall be used". The policy further stated that the "operator shall take relevant precautionary measures to avoid the contamination of organic sites and products. Where there is a reasonable suspicion of substantial contamination by, for example, soil, water, air, inputs or ingredients, appropriate actions shall be taken". It was further stated that "Iand converted to organic production shall not be alternated (switched back and forth) between organic and conventional production".

In South Africa, the policy on organic farming was coined and adopted from policies formulated by international organizations. The policy followed international standards such as the Codex Alimentarius, the European and American regulations and the International Federation of Organic Agriculture Movements, (IFOAM). The policy adopted the definition of organic farming as stated by the FAO/WHO Codex Alimentarius Commission as: "A holistic production management system which promotes and enhances agro-ecosystem health, including biodiversity, biological cycles and soil biological activity. The main emphasis was on the use of management practices in preference to the use of off-farm inputs. This is accomplished by using, agronomic, biological, and mechanical methods, as opposed to using synthetic materials, to fulfil any specific function within the system". However, the South African policy was underpinned by a legal frame work that makes provision for an environment that is not harmful to health or well-being of the populace and also an environment that is not only protected but for the benefit of present and future generations, through reasonable legislative and other measures and the prevention of pollution and ecological degradation. The key goals are similar to the EU Act but with an extension such as the "protection of consumers against 
false, misleading and unfounded claims and create the obligation for all producers to indicate the levels of inputs used in their produce". Furthermore, the organic products should improve the health of the populace and environment and improve access to better nutrition for all.

In some other parts of Asia and African countries, there are few or no proper documented guidelines on the operation of organic farming. Individuals' especially poor farmers have relied on domestic waste without having prior knowledge to their source and composition for agricultural purposes. (Hofmann 2013). In some countries such as India as reported by (Nunan 2000), municipal solid wastes are collected from street bins and markets or purchased from the municipal dumpsite and subsequently sold informally to peri-urban farmers. In this case, the wastes are applied directly (unsorted) and used for farming with the sole aim of increasing productivity. In Kano, Nigeria, 'taki', is widely used, which is a composition of manure, household waste, street sweepings and ash (Asomani-Boateng and Haight, 1999). Waste from tanneries and abattoirs have been used. The composition is unknown and could contain toxic materials since street sweepings is involved. It should be noted that from most of the developing countries in Africa, farmers benefit from composted urban waste and local streams, contaminated with effluents from various industries and household sewage, this may act as a reliable source of water for peasant farmers especially in regions where there is a known low annual rainfall (Binns et al. 2003; Maconachie, 2007). Recently in South Africa, the introduction of urinary diversionary toilets has favoured the use of human urine in agriculture (Mugivhisa and Olowoyo 2015). The use of human faeces as a source of organic amendments is also a common phenomenon and still been investigated (Kutu et al. 2010).

Generally, various guidelines mentioned above, before the preceding paragraph stipulated a proper and strict use of only "safe organic waste" for organic farming. There are new scientific findings which may punctuate the guidelines provided by the EU Act on the effects of sludge on land which may call for a much stricter limits on values for heavy metals and other emerging contaminants, which were not addressed initially (Suciu et al. 2015). On the other hand, peasant and poor farmers 
101

102

103

104

105

106

107

108

are unable to deal with the levels and amounts of toxic compounds that might be present in the organic waste due to increasing demand for food and lack of knowledge on the adverse effect of these toxic pollutants not only on the environment but eventually the consumers of the end products mostly locally. The main objective in regulating or controlling the use of organic waste for organic farming should stem from the concerns about human health and the protection of the environment. Regulation and certification might be adopted for farmers intending to export their product internationally. However, this might be difficult with peasant farmers who are only cultivating a handful portion of hectares of land or engaged in backyard farming just for livelihood. Regulations are therefore only useful with commercial farmers and may also favour the understanding of the different organic actors that have been codified and what organic agriculture means today (Rigby and Cáceres, 2001; Mugivhisa and Olowoyo, 2015).

The concept of organic farming contributing to more sustainable agriculture, improving health condition and protecting the environment is of great concern in the light of emerging persistent organic pollutants. Several issues as reported in literature are associated with the use of organic waste in agriculture. For instance, the use of human and animal wastes (faeces and urine) for the production of food, feed or fertilizer may include the possibility of disease transmission, uptake of pharmaceutical drugs by plants, presence of pharmaceutical drugs from animal faeces which may negate the gains derived from the use of the waste (Furedy and Chowdhury 96). Other emerging pollutants have also been reported either in water or in waste that may be used for organic farming. The present review will provide an overview on what has been reported in literature on the occurrence, behaviour and persistence of organic pollutants in waste used for organic farming. 


\subsection{Evidence of various types of organic pollutants in the environment and fate of organic farming.}

\subsubsection{Pharmaceuticals in water, soil and plants}

Presence of pharmaceutical residues such as antibiotics, analgesic and anti-retroviral drugs in water bodies have been reported in literature ( Frederic and Yves, 2014;Prasse et al, 2010; Schoeman et al, 2015; Sui et al. 2015; Shraim et al. 2017). Pharmaceutical drugs are used extensively for mammals (humans and animals). Once ingested or injected, they either become metabolized or unmetabolized and may be excreted through urine and faeces (Paltiel et al. 2016). Though urine accounts for $1 \%$ of the conventional wastewater volumetric flow, but it contributes approximately $64 \%$ of pharmaceuticals, $80 \%$ of nitrogen, and $50 \%$ of phosphorus to waste water body. Pharmaceuticals are partially degraded in the environment and as a result are likely to accumulate in water bodies.

Even though urine can be regarded as an excellent complete fertilizer of plants, which contains phosphorus, nitrogen and potassium, it also contains residues of pharmaceutical products even after it has been stored for a prolonged period of time as a treatment step (Winker, 2010). Hence the consumption of urine in organic farming goes with the risk of dispersing the pharmaceutical residues onto the agricultural fields (Winker et al. 2008). It has been shown that the pharmaceuticals are mainly excreted through urine (70\%) and only partially through the faeces accounting for the overall ecotoxicological risk of 50\% (Winker, 2010). Antibiotics were detected in urine that had been stored for more than a period of more than 1.5 years (Winker, 2010). A study conducted in two Hebrew universities on human exposure to wastewater-derived pharmaceuticals confirmed that pharmaceuticals such as carbamazepine was detected in human urine when the subjects consumed agricultural products irrigated with wastewater. Carbamazepine, is an anticonvulsant drug which can be detected in reclaimed wastewater, highly persistent in soil, and can be taken up by crops (Paltiel et al. 2016). The long-term persistence also of some pharmaceutical drugs such as antibiotics at low levels can promote the proliferation of antibiotic resistant bacteria in river base flows and may enhance the drug resistance of microorganisms (.Martínez 2008 and Watkinson et al. 2009). 
Despite a significant improvement in water treatment technology, certain pharmaceuticals drugs residue may not be removed totally from wastewater that may be used for irrigation even after treatment (Wood et al. 2015; Schoeman et al. 2015). In South Africa, for example, according to the report from WHO (2013), there are about 2, 150880 people placed on antiretroviral drugs in the fight against HIV/AIDS which is far more than any other nation. It is then logical to think that the residue of these drugs may be present in the environment. Wood et al. (2015) noted in a study conducted on the occurrence of anti-retroviral compounds used for HIV treatment in South African surface water that, nevirapine, a non-nucleoside reverse transcriptase inhibitor that is widely used for the treatment of HIV as well as the prevention of mother-to-child transmission was detected in all of the surface water samples used in the study and quantified in nine out of the 24 sampling locations. According to Vanková et al. (2010), the presence of this compound can be attributed either to its frequent therapeutic use or also the compound's persistence in the environment. The compound is reported to be non-biodegradable (Coovadia et al. 2012; Vanková et al. 2010). Similar study conducted by Schoeman et al. (2015) showed that concentrations of nevirapine and efavirenz in wastewater before treatment were high as 2100 and $17400 \mathrm{ngL}^{-1}$ respectively. However, upon treatment, $50 \%$ of the ARVDs were removed which resulted in the concentrations of nevirapine and efavirenz as high as 350 and $7100 \mathrm{ngL}^{-1}$ respectively. The study further reported that chlorination did not have any significant reduction in the concentrations of the ARVDs from the treated waste water, hence its presence in the wastewater after treatment.

Apart from the antiretroviral drugs, presence of antibiotics in treated wastewater have also been reported. Antibiotics can be released into hospital wastewater due to excretion of used antibiotics and improper disposal of unused or expired antibiotics (Michael et al. 2013). This may pose a significant health risk especially causing antibiotic resistance, by promoting the selection of antibiotic resistance genes and antibiotic resistant bacteria which may pose a serious threat to global public health (Kummerer 2009 and WHO 2014). The study of Lien et al. (2016) on antibiotics in wastewater 
of a rural and an urban hospital before and after wastewater treatment in Vietnam showed that ciprofloxacin and metronidazole were detected in hospital wastewater before and after the treatment. Similarly, Hussain et al. (2016) quantified the levels of ofloxacin (OFL), ciprofl oxacin (CIP), levofl oxacin (LEV), oxytetracycline (OTC), and doxycycline (DOX) in wastewater and reported that the antibiotics accumulated in wastewater and accumulated in soil and plants and later percolated to groundwater.

Several reports have shown advancement in various methods used for the removal of pharmaceutical drugs from wastewater, however, to the best of our knowledge and as at the time of writing this report, there are no methods reported in literature that have completely removed pharmaceuticals residues from wastewater. The study of Watkinson et al. (2007) showed that both conventional and advanced wastewater treatment plants significantly reduced antibiotic concentrations with an average removal rate from the liquid phase of $92 \%$. However, antibiotics were still detected in both effluents from the low-to-mid $\mathrm{ngL}^{-1}$ range. Ciprofloxacin, Sulphamethoxazole, lincomycin and trimethoprim were still detected in the wastewater after treatment. Li et al. (2014) in China noted that the advanced wastewater treatment facilities used in treating and removing antibiotics from wastewater did not remove all antibiotics completely. Most of the targeted antibiotics were detected in the secondary and tertiary effluents, with concentrations ranging from $4.8-1106.0$ and $0.3-505.0 \mathrm{ngL}^{-1}$. The study further showed that fluoroquinolone showed relatively high concentrations in all samples (782-1814 $\left.\mathrm{ngL}^{-1}\right)$. The study concluded that different tertiary treatment processes showed discrepancy in antibiotics removal. Similarly Becker et al. (2016) also reported that removal of antibiotics in wastewater by enzymatic treatment with fungal laccase did not reduce the load of antibiotics, however, the addition of syringaldehyde enhanced the degradation of 32 out of the 38 antibiotics by $50 \%$ after 24 hours.

With the presence of antibiotics in wastewater which may be used for irrigation, there are evidences that plants can bio accumulate and store these compounds in their tissue (Eggen and Lillo, 2012; 
200 Sabourin et al. 2012; Tanoue et al., 2012). The plant uptake, translocation and bioaccumulation of

201

202

203

204

205

206

207

208

209

210

211

212

213

214

215

216 pharmaceuticals in the edible parts of food crops and fodders have been reported (Tanoue et al. 2012; Wu et al. 2013; Christou et al. 2016, 2017). Hussain et al. (2016) conducted a study on accumulation of residual antibiotics in the vegetables irrigated by pharmaceutical wastewater and reported that ofloxacin, ciprofloxacin, levofloxacin, oxytetracycline and doxycycline were detected in soil and vegetables samples in surrounding areas of pharmaceutical industry. The order of pharmaceuticals contamination from the vegetables was in the order leaves $>$ stem/shoot $>$ root $>$ fruit. Also in a study conducted by Zheng et al. (2016) on the reuse of treated wastewater in agriculture, lettuce leaves showed very high bio concentration values for caffeine, carbamazepine, and sulfamethoxazole and hormones, indicating that these three compounds can easily translocate from lettuce roots to leaves and thereby accumulate in plant leaves. From the same study using tomato plants all the pharmaceutical products were only detected in the roots.

However, it is important to note that the translocation and uptake of these pharmaceuticals residue by plants are governed by various factors such as the soil $\mathrm{pH}$, soil organic matter content and the redox potential of the soil. Goldstein et al. (2014), reported that factors affecting the uptake of pharmaceuticals by crops irrigated with treated wastewater, includes the physiological nature of the plant, soil properties and water quality. Sabourin (2012) had initially suggested that there may be little risk of pharmaceuticals uptake into vegetable crops, if produced according to current mandated regulations that specify a one-year offset between biosolid application and crop harvest.

\subsubsection{Polycyclic Aromatic Hydrocarbons, PCBs and organic farming}

The presence of polycyclic aromatic hydrocarbons (PAH) in the environment may be both natural and anthropogenic sources, with the later acting as the major source of the PAHs in the environment (Ashraf and Salam 2012). PAHs are present in the air, water and soil, and can remain in the environment for months or years (EFSA 2008). PAHs may be as a result of incomplete combustion, due to the burning of fossil fuels during heating processes, waste incineration and from automobile 
exhausts (ATSDR, 2005). They are carcinogenic compounds and many studies have been carried out to identify the human exposure sources. Among those reported in literature to be carcinogenic are benzoanthracene, benzofluoranthene, benzopyrene and dibenzoanthracene (IARC 1983).

Gaseous deposition has been reported to be the main pathway of PAH presence in plants during the opening and closing of stomata, however, a direct relationship between soil and plant PAH concentrations have been observed indicating a possible soil uptake and translocation within the plant tissues from contaminated soils (Meudec et al. 2006).

In Europe, PAHs are frequently found in sludge at relatively high concentrations: $7.8-13.3 \mathrm{mg} \mathrm{kg}{ }^{1}$ (Kapanen et al. 2013; Rhind et al. 2013). In China, more than $1.9 \times 10^{4}$ hectares of farmland was contaminated by polycyclic aromatic hydrocarbons (PAHs) after long-term sewage irrigation (Li et al. 2008)). In countries where there are low temperatures and frequent soil freeze-thawing, the degradation of PAHs in soil is usually very slow and this may lead to high toxicity of residual PAHs in surface soil, which is harmful to the ecological environment and may contaminate agricultural products (Zhao et al. 2009). From most developing countries, where waste management is still a serious problem, application and disposal of sludge are done directly on the field which may contaminate the receiving soil intended for agriculture production. In some countires, such as France, Spain and UK, waste from sludge are deposited directly on land and may pose serious danger for farming activities (Kirchmann et al. 2017).

Reports from literature have suggested that soils contaminated with PAH either as a result of sludge application or through anthropogenic sources may pose serious danger for farming activities through the plant uptake of PAHs in soil (Fismes 2002; Meudec et al. 2006; Zhao et al. 2009 and Ashraf and Salam, 2012). The known and reported pathway for the presence of PAHs in plants includes root uptake from soil solution, followed by translocation from roots to shoots during transpiration and absorption by roots or shoots of volatilized organics from the surrounding air by shoots. The other major uptake from contaminated soil and dust may be retained in the cuticle or penetrate through 
250

251

252

253

254

255

256

257

258

259

260

261

262

263

264

265

266

267

268

269

270

271

272

uptake and transport in oil channels which are found in some oil-containing plants such as carrots (Topp et al. 1986; Duarte-Davidson and Jones, 1996 and Kacálková and Tlustoš 2011).

A study conducted by Fismes et al. (2002) showed presence of PAHs in soil and were detected in all plants grown in contaminated soils but low when compared to the levels in the soil except from peeled potatoes. The study further stated that root uptake was the main pathway for high molecular weight PAHs. Kacálková and Tlustoš (2011) also noted a high phenanthrene concentration in aboveground biomass of sunflower and high concentration of pyrene in maize roots. In a similar study conducted in India on the presence of PAHs in vegetables and fruits, high concentrations of PAH such as benzoanthracene, benzopyrene, benzofluoranthene and benzofluoranthene was recorded in cabbage $\left(8.34 \mu \mathrm{gg}^{-1}\right)$, which turned out to be more than any of the other fruit vegetables. The study further revealed a cumulative dietary exposure of PAHs ranging from 0.20 to $0.85 \mu \mathrm{g} \mathrm{p} \mathrm{p}^{-1} \mathrm{~d}^{-1}$ (Ashraf and Salam 2012).

PCBs on the other hand are usually referred to as a group of man-made organic chemicals consisting of carbon, hydrogen and chlorine atoms. They can also remain for long periods recycling between air, water and soil. They have been implicated in causing immune system disorders, dermatological problems, reproductive abnormalities, neuro-behavioral effects and cancer although conclusive cause and effect relationships are difficult to prove (Longnecker et al. 1997). The production of PCBs and many organochlorine compounds has been banned widely for many years in many countries such as America, Europe and other parts of the world, but their residues still remain as contaminants in the environment and food because of their long-term persistence and mobility (Rea, 1996; Lidstrom et al. 2002).

Just like the PAHs, PCBs accumulation in plants can occur through root uptake and translocation to upper plant parts, atmospheric deposition, uptake of both wet and dry contaminated particulates onto exposed plant surfaces and through uptake of airborne vapours by aerial plant parts via the stomata (Lovett et al. 1997). Witczak and Abdel-Gawad (2012) noted in a study on the presence 
polychlorinated biphenyls residues in vegetables, grain and soil from organic and conventional farming from Poland that $\mathrm{PCB}$ residues recorded in the beets from organic farming were high when compared with conventional farming system used.

\subsubsection{Toxic trace metals and organic farming}

The presence of trace metals in the environment may either come from natural or anthropogenic sources. An increase in the concentrations of trace metals in the environment has been a serious concern recently (Olowoyo et al. 2015). The increase especially from developing countries might be as a result of various developmental programmes that are embarked upon by these countries. With the increase in the amount of trace metals in the environment, they are thus present in air, water and soil. Major problem associated with trace metals in the environment is their non biodegrable nature and as a result they main remain within the ecosystem for a very long period.

According to Jan et al. (2010) food chain is one of the most important human exposure pathways to heavy metals after inhalation and dermal absorption. Several literature have suggested and demonstrated the ability of different plants to act either as an excluder or bioaccumulator of trace metals from the soil (Olowoyo et al. 2010; Nabulo et al. 2011; Lion and Olowoyo 2015). In the case of bioaccumulator, it is possible for plants to uptake or translocate these toxic metals within their tissue and other literatures have also suggested a foliar uptake in some plants (Tomasevic et al. 2010). However, with the bioaccumulators, several factors have been suggested that may affect the uptake of toxic trace metals and these factors include the concentration of heavy metals in soils, soil organic matter content, soil pH , type of the vegetables and species (Rafiq et al. 2014; Xu et al. 2015; Yang et al.2015).

The practice of organic farming is usually carried out with the use of farmyard manure, sewage sludge and also the reuse of treated wastewater for irrigation (Sarwar Qureshi et al. 2016; Nookabkaew et al. 2016 and Kirchmann et al. 2017). The farmyard manure (cow, pig and poultry) 
has been noted to contain various amount of different trace metals depending on the source and area where collected (Mortvedt 1996 and Gupta and Charles 1999). Over a prolonged period of time and with continuous application of farm yard manure that are contaminated this may result in land contamination by some potentially toxic elements such as arsenic ( $\mathrm{As})$, cadmium (Cd), and lead $(\mathrm{Pb})$ in agricultural soils and water resources. Zhao et al. (2014) demonstrated that the application of cattle manure increased soil organic matter content of the soil leading to high productivity but with an accumulation of heavy metals in corn that was fertilized with that cattle manure. The study conducted by Nookabkaew et al. (2016) also showed that concentrations of As and Cd in pig manure were higher than their levels in cattle manure. The study further showed that the use of pig manure as soil supplement resulted in high Cd contamination in Gynostemma pentaphyllum a herbal tea used for the study. It was further noted that there was a positive concentration for $\mathrm{Cd}$ in plants and the soil. Hence, the study concluded that the application of some organic fertilizers or animal manures to agricultural soil could increase some potentially toxic elements in soil, which may bedetrimental.

The use of treated and untreated wastewater in the urban and peri-urban areas of many developing countries use for irrigation is a common phenomenon (Tyagi et al. 2009; Singh et al. 2010). Farmers believed that undiluted wastewater provides nutrients and is cheaper than other water sources. However, the use of improperly treated and untreated wastewater for irrigation may come with serious problems such as the accumulation of heavy metals in agricultural soils and their uptake by food crops, which might be a potential health risk to the local inhabitants and, thus, increase the risk of contamination in agricultural products (Nabulo et al. 2010). In municipal wastewater treatment plants, human excreta are mixed with other effluents containing metals, organic residues, pharmaceuticals and pathogens (Östman et al. 2014). Khan et al. (2008) conducted a study in China, and reported that there is a build-up of heavy metals in wastewater - irrigated soils and this also increased the concentrations of trace metals in plants grown on the soil and the values recorded for 
some trace metals in the plants exceeded the permissible limit for human consumption. Weldegebriel et al. (2012) also reported in a study carried out in Ethiopia on the concentrations of trace metals in vegetables that the concentrations of $\mathrm{Pb}$ and $\mathrm{Cd}$ in the vegetables used for the study were above the permissible limit for human consumption. In the same vein, Sarwar Qureshi et al. (2016) also reported that higher concentrations of iron (Fe), copper (Cu), chromium ( $\mathrm{Cr}$ ) and zinc ( $\mathrm{Zn})$ were found in lettuce, radish and carrots irrigated with treated wastewater. The study of Wang et al. (2012) though reported that the levels of Cd exceeded the acceptable limit for agricultural land, however, the concentrations of the trace metals in soils and vegetables were all below the permissible limits set by the Ministry of Environmental Protection of China and World Health Organization.

On the other hand, the application of municipal sludge to agricultural land is an attractive option for disposal because of the possibility of improving soil properties and increasing plant productivity with the recycling of valuable components including organic matter (Liu et al. 2013). However, the use of sludge may also pose a serious danger for consumers of products coming from soil fertilized with sludge. Sludge has been known in some instances to contain high amount of toxic metals (Nabulo et al. 2006, 2010; Khan et al. 2007). Sewage sludge, is a byproduct of sewage treatment processes and made up of pathogenic microorganisms, organic and inorganic components Bourioug et al. 2016). Due to the presence of trace metals in sludge, several documented reports have suggested that it may be necessary to consider differences in metal affinity shown by specific vegetables and fruits before its application on agricultural lands and the soil pH (Bigdeli and Seilsepour, 2008; Li et al. 2007; Lion and Olowoyo 2015). Though concerted efforts have been made to optimize disposal practices by improving sludge treatment, concentrations of pathogens and other pollutants is still a matter of concern (Kelessidis and Stasinakis, 2012). The report from a study conducted by Adekunle et al. (2009) in Nigeria showed that the values of $\mathrm{Pb}$ in vegetables planted on soil after the application of sludge exceeded recommended values for human consumption. Similarly, Chary et al. 
349 (2008) and Singh et al. (2010) observed large $\mathrm{Zn}$ and Cd hazard quotients arising from consumption of vegetables grown on soil ligated with sewage in India.

\section{Conclusion}

With well documented information from literature, there is an overwhelming evidence that plants may uptake different types of both organic and inorganic pollutants from soil when cultivated on soils that are polluted or irrigated with polluted wastewater. Despite this evidence, the practice of organic farming involving the use of sludge, farm yard manure (animal faeces, human urine and faeces) treated and untreated wastewater and the collection of waste from different sources by peasant farmers is on the increase all over the world. Poor farmers and members of their immediate family may be at greater risk especially when organic materials are collected from sources that are unknown and are used for organic farming and production of food to sustain livelihood in all these households.

The legislation that establishes organic farming in most regions of the world provided guidance on how it should be practiced. For instance, the legislation mentioned the use of standard practice in the production of the organic products. Such standard practices includes strictly the use of nonhazardous materials for the farming purpose. However, this is mainly done with large scale farmers who intend to sell their products to any of the European countries. The question one tends to ask is the followings: who examines the products at the local levels especially for the poor farmers that collect waste on the streets? Are there any regulations or information that may guide these peasant farmers on the appropriate use and handling of sludge and waste collected on the streets? How equipped is the present technology as regards the removal of organic pollutants either from the sludge or wastewater? When the products are not for sale at the international market, who examines their safety for human consumption locally? 
373 The techniques involved in organic farming such as mulching, use of farm yard manure and 374 integration of crops and livestock are not entirely new to various agriculture practices. However, organic farming was established based on various laws and certification programs, which prohibit the use of almost all synthetic inputs, and health of the soil is recognized as the central theme of the method. Due to the presence and increase in the levels of emerging pollutants in the environment as established in this review, it may be necessary to provide holistic and adequate information on the pros and cons of organic farming if contaminated materials are used. The study of Mugivhisa and Olowoyo (2015) showed that the majority of respondents in their study had previous knowledge of organic farming but had failed to practise it because they could not afford it. In addition, they thought organic fertilizers, such as dry sewage, human faeces and human urine were unacceptable because of their smell, their unhygienic nature and the respondents' fear of disease epidemics. None of those interviewed had knowledge on the emerging pollutants and their impact on human health. However, half of those interviewed in the study are willing to convert to organic farming, if there are adequate information and education. It seems there are no adequate information as to safe handling and the use of these organic manures in agriculture within these groups of individuals.

Several proposals have been made on how to improve the use of sludge, wastewater and other materials used for organic farming. This should be intensified in order to minimise the risk that may be associated with organic farming. For instance, FAO (1992) revealed that sewage sludge should be subjected to biological, chemical or thermal treatment, long-term storage or other appropriate process designed to reduce its fermentability and health hazards resulting from its use before being applied in agriculture as fertilizer (FAO, 1992). Carnus (2006) also mentioned that when sludge is applied there should be an intensive monitoring of ecosystem components such as plants, soil, water and fauna to identify any possible positive or negative impacts of sludge on plant productivity, on the environment and on human health. 
397 The use of human urine or excreta as reported by Andersson (2015) may be safe but collection methods and storage capacity should be improved in order to promote safe use especially for peasant farmers. South Africa and other countries have urine diversionary toilet which facilitates the collection and safe use of urine (Mugivhisa and Olowoyo 2015). Since studies have also shown that human urine may contain traceable concentrations of antibiotics or analgesic, it will then be advisable that urine of those on antibiotics or analgesic should not be used for organic farming (Jin 2010; Zhi et al. 2011 and Wang 2014). An ongoing study from Mugivhisa and Olowoyo (2016) have shown that spinach fertilized with urine that contains antibiotics have a traceable amount of the antibiotics in the vegetable. Similar observation had earlier been made by Wu et al. (2013) where antibiotics were detected in the vegetable used for the study.

Generally, it was never the intention of the authors to discredit organic farming especially looking at the enormous advantage posed by it for poor people, however, strict guideline and adequate information should be provided by government agency on the safe practice of organic farming so that the unexpected negative impact will not overshadow the positive aspect of the farming method.

Improved and renewed efforts need to be geared towards the removal of persistent organic pollutants in the environment. This may include the introduction of new technology within the waste treatment plants and research into the ability of different plants that can bioaccumulate these pollutants from the soil.

It is also the view of the authors that concerted effort should be placed on the awareness, training and education of the peasant farmers on how, when and the type of organic materials that should be used for organic farming in line with the legislation. 
421

422

423

424

425

426

427

428

429

430

431

432

433

434

435

436

437

438

439

440

441

442

443

\section{ACKNOWLEGDEMENT}

The authors are very grateful for the funding received from NRF under the CSUR 2017. This has made the exchange programme to the University of Saskatchewan, Saskatoon in Canada possible. The understanding and leave of absence granted Prof Olowoyo JO during his short visit to University of Saskatchewan by Sefako Makgatho Health Sciences is greatly appreciated.

\section{REFERENCES}

Adekunle, I., Olurundare, O. and Nwange, C. (2009). Assessments of Pb levels and daily intakes from green leafy vegetables of southwest Nigeria. Nutrition \& Food Science, 39(4): 413-422.

Agency for Toxic Substances and Disease Registry (ATSDR). 1995. Toxicological profile for automotive gasoline. Atlanta, GA: U.S. Department of Health and Human Services, Public Health Service.

Altenbuchner, C., Vogel, S. and Larcher, M. (2017). Social, economic and environmental impacts of organic cotton production on the livelihood of smallholder farmers in Odisha, India. Renewable Agriculture \& Food Systems. Doi.org/10.1017/S174217051700014X.

Andersson, E. (2015). Turning waste into value: using human urine to enrich soils. Applied Energy, 131(3): 345-367.

Ashraf, M.W., and Salam, A. (2012). Polycyclic aromatic hydrocarbons (PAHs) in vegetables and fruits produced in Saudi Arabia. Bulletin of Environmental Contamination \& Toxicology, 88(4):543-547.

Asomani-Boateng, R., and Haight, M. (2007). Reusing organic solid waste in urban farming in African cities: a challenge for urban planners. Third World Planning Review (1999), 21(4): 411-423.

Becker, D., Giustina, S.V.D. and Rodríguez-Mozaz, S. (2016). Removal of antibiotics in wastewater by enzymatic treatment with fungal laccase - Degradation of compounds does not always eliminate toxicity. Bioresource Technology, 219: 500-509. 
444 Benbrahim, M., Denaix, L., Thomas, A.L., Balet, J. and Carnus J.M. (2006). Metal concentrations in edible mushrooms following municipal sludge application on forest land. Environmental Pollution, 144(3): $847-854$.

Bigdeli, M. and Seilsepour, M. (2008). Investigation of metals accumulation in some vegetables irrigated with waste water in Shahre Rey-Iran and toxicological implications. American Eurasian Journal of Agricultural \& Environmental Sciences, 4 (1): 86-92.

Binns, J. A., Maconachie, R.A. and Tanko, A.I. (2003). Water, and health in urban and periurban food production: The case of Kano, Nigeria. Land Degradation Development, 14: 431-444.

Bourioug, M., Alaoui-Sehmer, L. Laffray, X. Benbrahim, M. Aleya, L. and Alaoui-Sossé, B. (2015). Sewage sludge fertilization in larch seedlings: Effects on trace metal accumulation and growth performance. Ecological Engineering, 77: 216-224.

Chary, N.S., Kamala, C.T. and Raj, D.S.S. (2007). Assessing risk of heavy metals from consuming food grown on sewage irrigated soils and food chain transfer. Ecotoxicology \& Environmental Safety, 69(3): 513-524.

Christou, A., Antoniou, C. Christodoulou, C. Hapeshi, E. Stavrou, I. Michael, C. Fatta-Kassinos, D. and Fotopoulos, V. (2016). Stress-related phenomena and detoxi- fication mechanisms induced by common pharmaceuticals in alfalfa (Medicago sativa L.) plants, Science of the Total Environment, $557-558,652-664$.

Christou, A., Karaolia, P. Hapeshi, E. Michael, C. and FattaKassinos, D. (2017), Long-term wastewater irrigation of vegetables in real agricultural systems: Concentration of pharmaceuticals in soil, uptake and bioaccumulation in tomato fruits and human health risk assessment. Water Research, 109, 2434. 
Eshleman, S.H. Richardson, P. George, K. Andrew, P. Mofenson, L.M. Zwerski, S. Maldonado, Y. (2012). HPTN 046 protocol team. Lancet, 379(9812): 221-228.

Duarte-Davidson, R., and Jones, K. C. (1996). Screening the environmental fate of organic contaminants in sewage sludge applied to agricultural soils. II. The potential for transfers to plants and grazing animals', Science of the Total Environment, 185: 59-70.

Eggen, T. and Lillo, C. (2012). Antidiabetic II drug metformin in plants: uptake and translocation to edible parts of cereals, oily seeds, beans, tomato, squash, carrots, and potatoes. Journal of agricultural \& food chemistry, 60(28): 6929-6935.

FAO. (1992) Wastewater treatment and use in agriculture - FAO irrigation and drainage paper 47. FAO, Rome. 144 p.

Farnworth, C. and Hutchings, J. (2009). Organic Agriculture and Women's Empowerment. International Federation of Organic Agriculture Movements, Bonn. IFOAM, Germany.

Fismes, J., Perrin-Ganier, C., Empereur-Bissonnet, P. and Morel, J.L. (2002). Soil-to-root transfer and translocation of polycyclic aromatic hydrocarbons by vegetables grown on industrial contaminated soils. Journal of Environmental Quality, 31(5):1649-56.

Frederic, O. and Yves, P. (2014). Pharmaceuticals in hospital wastewater: their ecotoxicity and contribution to the environmental hazard of the effluent. Chemosphere, 115: 31-39.

Furedy, C. and Chowdrury, T. (1996). Solid waste reuse and urban agriculture: Dilemmas in developing countries. The bad news and the good news. Paper presented at Joint Congress of Association of Collegiate Schools of Planning and Association of European Schools of Planning. Toronto. Available at http:/www.cityfarmer.org/Furedy.html.

Goldstein, M., Shenker, M. and Chefetz, B. (2014). Insights into the Uptake Processes of WastewaterBorne Pharmaceuticals by Vegetables. Environmental Science \& Technology, (48): 5593-5600. 
491 Gupta, G. and Charles, S. (1999). Trace elements in soils fertilized with poultry litter. Poultry Science,

492

493

494

495

496

497

498

499

500

501

502

503

504

505

506

507

508

509

510

511

512 78: 1695-1698.

Hofman, P. (2013). Wasted waste-Disappearing reuse at the peri-urban interface. Environmental Science \& Policy, 31: 13-22.

Hussain, S., Naeem, M. and Nawaz, C.M. (2016). Estimation of Residual Antibiotics in Pharmaceutical Effluents and their Fate in Affected Areas. Polish Journal of Environmental Studies, (25): Doi 10.15244/pjoes/61229.

IARC. 1983. Polynuclear Aromatic Compounds, Part 1. Chemical, Environmental and Experimental Data. IARC Monographs on the Evaluation of Carcinogenic Risk of Chemicals to Humans, vol. 32. Lyon, France: International Agency for Research on Cancer. Pp 477.

Jan, F.A., Ishaq, M., Khan, S., Ihsanullah, I., Ahmad, I. and Shakirullah, M. (2010). A comparative study of human health risks via consumption of food crops grown on wastewater irrigated soil (Peshawar) and relatively clean water irrigated soil (lower Dir). Journal of Hazardous Materials, (179): 612-621

Joshua, W.D. and Michalk, L.H. (1992). FAO, “Agricultural Use of Sewage," Waste Water Treatment and Use in Agriculture, FAO Irrigation and Drawing Paper 47, Food and Agriculture Organization of the United Nations, Rome, 1992.

Kacálková, L. and Tlustoš, P. (2011). The uptake of persistent organic pollutants by plants. Open Life Sciences, 6: 223-235.

Kapanen, A. Vikman, M. Rajasärkkä, J. and Virta, M. (2013). Biotests for environmental quality assessment of composted sewage sludge. Waste Management, 33(6): 1451-1460.

Kelessidisa, A. and Stasinakis, A.S. (2012). Comparative study of the methods used for treatment and final disposal of sewage sludge in European countries. Waste Management, 32: 1186-1195. 
513 Khan, J.A., Iqbal, Z., Rahman, S.U., Farzana,K. and Khan, A. (2008). Prevalence and resistance pattern 514 of Pseudomonas aeruginosa against various antibiotics. Pakistan Journal of Pharmaceutical Sciences, $51521(3): 311-315$

516 Khan, S.A., Mulvaney, R.L., Ellsworth, T.R. and Boast, C.W. (2007). The myth of nitrogen fertilization 517 for soil carbon sequestration. Journal of Environmental Quality, 36: 1821-1832.

Kirchmann, H., Börjesson, G., Kätterer, T. and Cohen, Y. (2017). From agricultural use of sewage sludge to nutrient extraction: A soil science outlook. Ambio, 46(2): 143-154.

Kümmerer, K. (2009). Antibiotics in the aquatic environment--a review--part I. Chemosphere, (4): 417-434.

Kutu, F.R., Muchaonyerwa, P. and Mnkeni, P.N.S. (2010). Complementary nutrient effects of separately collected human faeces and urine on the yield and nutrient uptake of spinach (Spinacia oleracea). Waste Management \& Research, 29(5): 532-539.

Li, X.W., Xie, Y.F., Li, C.L., Zhao, H.N., Zhao, H. and Wang, N. (2014). Investigation of residual fluoroquinolones in a soil-vegetable system in an intensive vegetable cultivation area in Northern China. Science of the Total Environment, 46: 58-264.

Li, Z., Sandau, C.D., Romanoff, L.C., Caudill, S.P., Sjodin, A., Needham, L.L. and Patterson, D.G. (2008). 529 Concentration and profile of 22 urinary polycyclic aromatic hydrocarbon metabolites in the US 530 population. Environmental Research, (107): 320-331.

531 Lien, L.T.Q., Hoa, N.Q., Chuc, N.T.K., Thoa, N.T.M., Phuc, H.D., Diwan, V., Dat, N.T., Tamhankar, A.J. 532 and Lundborg, C.S. (2016). Antibiotics in Wastewater of a Rural and an Urban Hospital before and 533 after Wastewater Treatment, and the Relationship with Antibiotic Use-A One Year Study from 534 Vietnam. International Journal of Environmental Research and Public Health, 13(6): 588. Doi: 10.3390/ijerph13060588. 
536 Lindström, G., Huag, L.S. and Dybing, T.N. (2002). Comparability of world-wide analytical data of

537 PCDDs, PCDFs and non-ortho PCBs in samples of chicken, butter and salmon. Chemosphere, 47(2):

538 139-146.

Lion, G.N. and Olowoyo, J.O. (2015). Urban farming as a possible source of trace metals in human diets. South African Journal of Science, 112 (1/2): 1-6.

Liu, W., Sun, W., Borthwick, A.G.L. and Ni, J. (2013). “Comparison on aggregation and sedimentation of titanium dioxide, titanate nanotubes and titanate nanotubes-TiO2: Influence of $\mathrm{pH}$, ionic strength and natural organic matter." Colloids and Surfaces A: Physicochemical and Engineering Aspects, 434: 319-328.

Longnecker, M.P., Rogan, W.J., Lucier, G. (1997). The human health effects of DDT (dichlorodiphenyltrichloroethane) and PCBs (polychlorinated biphenyls) and an overview of organochlorines in public health. Annual Review of Public Health, 18: 211-244.

Lovett, G.M., Bowser, J.J., and Edgerton, E.S. (1997). Atmospheric deposition to watersheds in complex terrain. Hydrolological Processes, 11:645-654.

Maconachie, R. (2007). Urban growth and land degradation in developing cities: Change and challenges in Kano, Nigeria. Ashgate Publishing Limited, Hampshire.

Martinez, J.L., (2008). Antibiotics and antibiotic resistance genes in natural environments. Science, 321: 365-367. MCoovadia, H., ,Brown, H.M., Fowler, E.R., Chipato, M.G., Moodley, T.D., Manji, K., Musoke, P., Stranix-Chibanda, L., Chetty, V., Fawzi, W., Nakabiito, C. Msweli, L. Kisenge R., Guay, L. Mwatha, A., Lynn, D.J., Eshleman, E.S., Richardson, P. and Maldonado, P. (2012). Efficacy and safety of an extended nevirapine regimen in infant children of breastfeeding mothers with HIV-1 infection for prevention of postnatal HIV-1 transmission (HPTN 046): A randomised, double-blind, placebocontrolled trial. The lancet, 379(9812): 221-228. 
560 Meudec, A., Dussauze, J., Deslandes, E. and Poupart, N. (2006). Evidence for bioaccumulation of

561

562

563

564

565

566

567

568

569

570

571

572

573

574

575

576

577

578

579

580

581

PAHs within internal shoot tissues by a halophytic plant artificially exposed to petroleum-polluted sediments. Chemosphere, 65: 474- 81. 10.1016/j. Chemosphere,01.058.

Michael, I., Rizzo L., McArdell C. S., Manaia C. M., Merlin C., Schwartz T., et al.. (2013). Urban waste water treatment plants as hotspots for the release of antibiotics in the environment: a review. Water Resources, 47: 957-993.

Mortvedt, J.J. (1996). Heavy metal contaminants in inorganic and organic fertilizers. In: RodriguezBarrueco C. (eds) Fertilizers and Environment. Developments in Plant and Soil Sciences, Vol 66. Springer, Dordrecht. DOIhttps://doi.org/10.1007/978-94-009-1586-2_2.

Mugivhisa, L.L. and Olowoyo, J.O. (2015). An assessment of university students and staff perceptions regarding the use of human urine as a valuable soil nutrient in South Africa. African Health Sciences, 15(3): 999-1010.

Nabulo, G., H. Oryem-Origa and M. Diamond, M. (2006). Assessment of lead, cadmium, and zinc contamination of roadside soils, surface films, and vegetables in Kampala City, Uganda. Environmental Research, 101: 42-52.

Nabulo, G., Young, S.D. and Black, C.R. (2010). Assessing risk to human health from tropical leaf vegetables grown on contaminated urban soils. Science of the Total Environment, 408: 5338-5351.

Nabulo, G., Black, C.R. and Young, S.D. (2011). Trace metal uptake by tropical vegetables grown on soil amended with urban sewage sludge. Environmental Pollution, 159(2): 368-376.

Nookabkaew, S., Rangkadilok, N., Prachoom, N., Satayavivad, J. (2016). Concentrations of trace elements in organic fertilizers and animal manures and feeds and cadmium contamination in herbal tea (Gynostemma pentaphyllum Makino). Journal of Agricultural and Food Chemistry, 64(16): 31193126. 
Nunan, F. (2000). Urban organic waste markets: responding to change in Hubli-Dharwad, India.

Habitat International, 24: 347-360.

585

Olowoyo, J.O., Mugivhisa, L.L. and Busa, N.M. (2015). Trace Metals in Soil and Plants around a

Cement Factory in Pretoria, South Africa. Polish Journal of Environmental Studies, 24(5): 2087-2093.

587

Olowoyo, J.O., Van Heerden, E., Fischer, J.L. and Baker, C. (2010). Trace metals in soil and leaves

of Jacaranda mimosifolia in Tshwane area, South Africa. Atmospheric Environment, 44: 1826-1830.

Östman, M., Fick, J., Näsström, E. and Lindberg, R.H. A (2014). Snapshot of illicit drug use in Sweden acquired through sewage water analysis. Science of the Total Environment, 472: 862-871.

591

Paltiel, O, Ganna Fedorova, G., Galit Tadmor, G and Benny Chefetz, B. (2016). Human Exposure to

Wastewater-Derived Pharmaceuticals in Fresh Produce: A Randomized Controlled Trial Focusing on Carbamazepine. Environmental Pollution, 213: 308-313.

Pescod, M.B. (1992). Food and Agriculture Organization of the United Nations. Wastewater treatment and use in agriculture - Food and Agriculture Organization of the United Nations, Rome. FAO irrigation and drainage paper 47.

597

Prasse, C., Schlusener, M.P., Schulz, R. and Ternes, T.A. (2010). Antiviral drugs in wastewater and surface waters: a new pharmaceutical class of environmental relevance? Environmental Scientific Technology, 44: 1728-1735.

600

Qureshi, A.S., Hussain, M.I., Ismail, S. and Khan, Q.M. (2016). Evaluating heavy metal accumulation and potential health risks in vegetables irrigated with treated wastewater. Chemosphere, 163: 54-61. 
606 Rhind, S.M., Kyle, C.E., Kerr, C., Osprey, M., Zhang, Z.L., Duff, E.I., Lilly, A., Nolan, A., Hudson, G., 607 Towers, W., Bell. J., Coul, M. and McKenzie, C. (2013). Concentrations and geographic distribution of 608 selected organic pollutants in Scottish surface soils. Environmental Pollution, (182):15-27.

Rigby, D. and Caceres, D. (2001). Organic farming and the sustainability of agricultural systems. Agricultural Systems, 68: 21-40.

Rigby, D., Young, T. and Burton, M. (2001). The development of and prospects for organic farming in the UK. Food Policy, 26: 599-613.

Sabourin, L., Duenk, P. Bonte-Gelok, S., Payne, M, Lapen, D.R. and Topp, E. (2012). Uptake of pharmaceuticals, hormones and parabens into vegetables grown in soil fertilized with municipal biosolids. Science of the Total Environment, 431: 233-236.

Schoeman, C., Mashiane, M., Dlamini, M. and Okonkwo, O.J. (2015). Quantification of Selected Antiretroviral Drugs in a Wastewater Treatment Works in South Africa Using GC-TOFMS. Journal of Chromatography \& Separation Techniques, 6: 272.

Scialabba, N. and Hattam, H. (2002). Organic agriculture. Environment, and Food Security.

Scientific Opinion of the Panel on Contaminants in the Food Chain on a request from the European

Seufert, V. and Ramankutty, N. (2017). Many shades of gray - The context-dependent performance or organic agriculture. Sciences Advances,3(3): e1602638. Doi: 10.1126/sciadv.1602638. Arabian Journal of Chemistry, 10(1): 719-729.

Singh, A., Sharma, R. K., Agrawal, M. and Marshall, F.M. (2010). Risk assessment of heavy metal toxicity through contaminated vegetables from waste water irrigated area of Varanasi, India. 
630 Suciu, N.A., Lamastra, L. and Trevisan, M. (2015). PAHs content of sewage sludge in Europe and its 631 use as soil fertilizer. Waste management, 41:119-127.

632 Sui, Q., Cao, X., Lu, S., Zhao, W., Qiu, Z., and Yu, G. (2015). Occurrence, sources and fate of 633 pharmaceuticals and personal care products in the groundwater: a review. Emerging Contaminants,

634 1: $14-24$.

635 Tanoue, R., Sato, Y., Motoyamam, M, Nakagawam, S, Shinohara, R. and Nomiyama, K. (2012). Plant uptake of pharmaceutical chemicals detected in recycled organic manure and reclaimed wastewater. Journal of Agriculture \& Food Chemistry, 60:10203-11021. organic chemicals by plants from soil. Ecotoxicology \& Environmental Safety, 11: 219-228. groundwater under intensive agricultural landuse. Asian Journal of Water, Environment \& Pollution, 6(2): 81-86.

Vanková, M., others, 2010. Biodegradability analysis of pharmaceuticals used in developing countries; screening with OxiTop C-110.http:/urn.fi/URN:NBN:fi:amk-2010120817546. soils. Environmental Chemistry, 31: 763-770. primary health care settings in China. JAMA Internal Medicine, 174(12): 1914-1920. 
651 Watkinson, A.J., Murby, E.J. and Costanzo, S.D. (2007). Removal of antibiotics in conventional and

652 advanced wastewater treatment: Implications for environmental discharge and wastewater 653 recycling. Water Research, 41(18): 4164-417.

654

Watkinson, A.J, Murby, E.J., Kolpin, D.W. and Costanzo, S.D. (2009). The occurrence of antibiotics in an urban watershed: From wastewater to drinking water. Science of the Total Environment, 407(8):

656 2711-2723.

657

Weldegebriel, Y., Chandravanshi, B.S. and Wondimu, T. (2012). Concentration levels of metals in vegetables grown in soils irrigated with riverwater in Addis Ababa, Ethiopia. Ecotoxicoogy and Environmental Safety, 77:57-63.

Witczak, A. and Abdel-Gawad, H. (2012). Comparison of organochlorine pesticides and polychlorinated biphenyls residues in vegetables, grain and soil from organic and conventional farming in Poland. Journal of Environmental Science and Health, Part B V 47 (4): 343-354.

Wood, T.P., Duvenage, C.S.J. and Rohwer, E. (2015). The occurrence of anti-retroviral compounds used for HIV treatment in South African surface water. Environmental Pollution, 199: 235-243.

World Health Organization (WHO). (2013). Consolidated Guidelines on the use of antiretroviral drugs for treating and preventing HIV Infection; Geneva. Available from: www.who.int/hiv/pub/guidelines/arv2013

World Health Organization (WHO). (2014). Antimicrobial resistance: global report on surveillance. Number of pages: 257. Publication date: April 2014. Languages: English. ISBN: 9789241564748

Wu, X., Ernst, F., Conkle, J. L., and Gan, J. (2013). Comparative uptake and translocation of pharmaceutical and personal care products (PPCPs) by common vegetables. Environment International, 60: 15-22. 
675 Xu, L., Wang, Y., Liu, W., Wang, J., Zhu, X. and Zhang, K. (2015). De novo sequencing of root 676 transcriptome reveals complex cadmium-responsive regulatory networks in radish (Raphanus sativus 677 L.). Plant Science, 236, 313-323. 10.1016/j.plantsci.2015.04.015.

678 Yang, Y., Song, Y., Scheller, H.V., Ghosh, A., Ban, Y., Chen, H. and Tang, M. (2015). Community 679 structure of arbuscular mycorrhizal fungi associated with Robinia pseudoacacia in uncontaminated 680 and heavy metal contaminated soils. Soil Biology \& Biochemistry, 86: 146-158.

681 Zhao, H., Yin, C., Chen, M., Wang, W., Jefferies, C. and Shan, B. (2009). Size distribution and diffuse 682 pollution impacts of PAHs in street dust in urban streams in the Yangtze River Delta. Journal of 683 environmental sciences (China), 21: 162-7. 10.1016/S1001-0742(08)62245-7.

684 Zhao, P., Shen, Y., Ge, Z., Chen, G.Z. and Yoshikawa, K. (2014). Clean solid biofuel production from 685 high moisture content waste biomass employing hydrothermal treatment. Applied Energy, 131: 345-

686 367.

687 Zheng Z, Yang M, Zeng Y, Wu J, Qiu K, Huang H. (2017)Changing the perspective of off-label drug use 688 in China. BMJ (Blog). Available from: http:// blogs.bmj.com/bmj/2016/01/12/zhihua-zheng-etalchanging-the-perspective-of-off-label-drug-use-in-china/. Accessed January 5, 2017. 